\title{
Resistance Evaluation of the Acerola (Malphigia emarginata D.C.) Seed to Compression
}

\author{
A. Figueiredo Neto ${ }^{1}$, Marcos A. Silva Irmão ${ }^{1}$, J. P. Alencar Junior ${ }^{1} \&$ R. M. Carneiro ${ }^{2}$ \\ ${ }^{1}$ Department of Agricultural Engineering, Federal University of San Francisco Valley of Management, \\ Engineering Campus, Juazeiro, Bahia, Brazil \\ ${ }^{2}$ Brazilian Agricultural Research Company, Petrolina, Pernambuco, Brazil \\ Correspondence: A. Figueiredo Neto, Department of Agricultural Engineering, Federal University of San \\ Francisco Valley of Management, Engineering Campus, Juazeiro, Bahia 48902-300, Brazil. Tel: \\ 55-74-2102-7621. E-mail: acacio.figueiredo@univasf.edu.br
}

Received: May 26, 2017

Accepted: June 26, 2017

Online Published: July 15, 2017

doi:10.5539/jas.v9n8p167

URL: https://doi.org/10.5539/jas.v9n8p167

The research is financed by FAPESB (Foundation of Research Support of the State of Bahia/Brazil).

\begin{abstract}
The objectives of this work were to verify the moisture content influence on the maximum compression force values, to determine the Proportional Modulus of Deformation, the Maximum Tangent and Secant for acerola seeds under compression on its natural repose position and for fixed deformations. Acerola seeds with moisture content varying from 0.12 to 0.46 (d.b.) compressed uniaxially between two parallel rigid plates. It can be concluded that the compression needed for deforming the acerola seeds decreases as its moisture content increases when the deformation values were within 19.2 and 548.8 N. The Proportional Modulus of Deformation increases with the reduction of the moisture content, where values found were within 5.2 to $72.1 \times 10^{7} \mathrm{~Pa}$. The sigmoidal model represented resistance to the compression of the acerola seeds adequately for different moisture content.
\end{abstract}

Keywords: post-harvest, firmness, rupture force

\section{Introduction}

The fruit of the acerola (Malpighia emarginata D.C.) is a drupacea berry which has three seeds, each surrounded by a lattice core and very resistant. The seeds are small, not containing albumen and of variable sizes, proportional to the size of the fruits. These seeds have low germination percentage, and may, depending on the degree of maturity, take months to germinate, and the seeds usually remain dormant for future germination (Costa et al., 2003).

Propagation by seed is problematic for the culture of acerola, because in many cases, there is numbness or lack of embryo, invalidating the production of seedlings. Another option of use is the industrialization of the acerola to obtain flour, which is an alternative to diversify the possibilities of commercialization of the fruits, which allows an increase of stability and reduces the postharvest losses of the product, making storage possible in environmental conditions for a longer time and allowing consumption of the product outside the harvest season (Reis et al., 2017).

The study of mechanical characteristics of agricultural products is important in order to design equipment operating for maximum efficiency with final product quality commitment. Shirmohammadi and Yarlagadda (2012) reported studying the behaviours of agricultural crops under different industrial operations which will help researches and designers to optimize and design new technologies to diminish unwanted deformations and total energy usage.

Knowledge of biological materials resistance is of utmost importance to facilitate procedures that can improve the performance of various cultures in germination for seedlings in the field.

Within several mechanical properties, the Modulus of Deformability allows making comparisons of relative resistances within different materials. To determine the Modulus of Deformability of a product, separation from 
the total deformation in two components, elastic and plastic, are needed. Obtaining the curve of forces in function of the Total Deformation, the Total Modulus of Deformability is obtained. According to Couto et al. (2002) and Figueiredo Neto et al. (2013) in their study on the mechanical behavior of a material, the Modulus of Deformability is considered more significant than those of elasticity because when a product is compressed, the Total Deformation has more practical application.

According to ASAE (2003), the Apparent Modulus of Deformability of a convex body could be determined through the following expression:

$$
E=\frac{0.531 \cdot F \cdot\left(1-\mu^{2}\right)}{D^{3 / 2}} \cdot\left[2 \cdot\left(\frac{1}{r}+\frac{1}{R}\right)^{1 / 3}\right]^{3 / 2}
$$

Where,

E: Modulus of Deformability, Pa; F: Compression force, N; D: Total Deformation (elastic e plastic) of the body in the contact points of the upper and the lower plate, m; $\mu$ : Poisson's ratio; $R, r$ : Radius of Curvature on the contact point, $\mathrm{m}$.

The Modulus of Deformability is a function of Poisson's ratio that assumes constant values for each material, but its value is still unknown for acerola seeds. In the absence of these values, Batista et al. (2003) used another variable proportional to de modulus of deformability and named it Proportional Modulus of Deformability that could be expressed as follow:

$$
\mathrm{Ep}=\frac{\mathrm{E}}{\left(1-\mu^{2}\right)}=\frac{0.531 \cdot \mathrm{F}}{\mathrm{D}^{3 / 2}} \cdot\left[2 \cdot\left(\frac{1}{\mathrm{r}}+\frac{1}{\mathrm{R}}\right)^{1 / 3}\right]^{3 / 2}
$$

Where,

Ep: Proportional Modulus of Deformability, Pa.

To determine the Proportional Modulus of Deformability of coffee fruits in different ripeness stages such as green, greenish and cherry ripeness with different moisture content, Couto et al. (2002) concluded that the Proportional Modulus of Deformability decreases as the fruits deformation increased.

Several factors affect the mechanical properties of the agricultural products, where drying air temperature and moisture content stood out (Mohsenin, 1986; Li et al., 1989; Zhang et al., 1989).

Several researchers asseverate that the drying air temperature is one of factor that most affect the mechanical properties of the agricultural products (Gustafson \& Hall, 1972; White et al., 1982; Corrêa et al., 2008).

Gupta and Das (2000) evaluating the mechanical behavior of the sunflower seeds found out that increasing the moisture content from 3.8 to $16.6 \%$ (w.b.), the force for rupturing the product was reduced and the deformation increased.

Oliveros-Tascón et al. (2002) evaluated the influence of the coffee worm infestation according to the cherry fruits and parchment coffee firmness (dry and humid) submitted to the compression tests. For the strawberry fruit there was no significant difference in terms of its firmness of sound and worm infested fruits (Jamieson et al., 2002).

Considering as exposed and the lack of theoretical information in specialized literature about the mechanical properties of acerola seeds, the present work aimed to determine the influence of moisture content on the compression maximum force values as to determine the Proportional Modulus of Deformability, the Maximum Tangent and Secant for the acerola seeds under compression in its natural repose position and for fixed deformations.

\section{Materials and Methods}

The present work was conducted in the Agricultural Products Storage Laboratory of the Federal University of Vale do São Francisco, at the engineering campus, Brazil.

Acerola seeds (Malphigia emarginata D.C.) of the 'Okinawa' variety was hand harvested with moisture content of approximately 0.46 (d.b.). After harvesting, the fruits were transported to the laboratory where they were washed and characterized as shown in Table 1, eliminating malformed and damaged fruits. 
Table 1. Characterization of acerola fruits, variety 'Okinawa', produced in the semiarid region of the São Francisco River Valley

\begin{tabular}{|c|c|c|c|c|c|c|}
\hline & Mass (g) & Fiber content $(\mathrm{g})$ & Protein contente $(\mathrm{g})$ & Carbohydrates (g) & Soluble solids ( ${ }^{\circ}$ Brix $)$ & Vitamin $C(\mathrm{mg} / 100 \mathrm{~g})$ \\
\hline Acerola 'Okinawa' & 9.2 & 1.1 & 0.40 & 7.96 & 12 & 3.260 \\
\hline
\end{tabular}

Different moisture content levels were obtained in a ventilated oven under temperature of $40 \pm 1{ }^{\circ} \mathrm{C}$ and Relative Humidity of $23 \%$. The reduction of water content was attended by the gravimetric method (weight loss), where knowing the initial weight of the product submitted for drying until the final moisture content of 0.12 (d.b.) by the use of an analytical scale with a precision of $0.01 \mathrm{~g}$.

The moisture content was determined by the oven method at $105 \pm 1{ }^{\circ} \mathrm{C}$, until the constant weight was achieved. For every moisture contents obtained, the samples were homogenized and conducted for mechanical properties determination under controlled temperature of $25^{\circ} \mathrm{C}$.

The compression tests were conducted for individual seeds by the use of a Universal Test Machine model "TA Hdi Texture Analyser", with load cell of $500 \mathrm{~N}$.

For each moisture contents, ten acerola seeds were submitted to the uniaxial compression between two rigid parallel plates, applied on the natural repose position, under force application at rate of $0.001 \mathrm{~m} \mathrm{~s}^{-1}$. The essay was finalized when the deformation had reached $0.002 \mathrm{~m}$.

The Proportional Modulus of Deformability of the acerola seeds (Ep), was determined according to the expression 2, where the deformations values obtained were: $0.4 ; 0.8 ; 1.2 ; 1.6$; and $2.0 \times 10^{-3} \mathrm{~m}$.

\section{Results and Discussion}

Table 2 presents the average values of the Radius of Curvature of the acerola seeds for each moisture level that was used in calculation to determine the Proportional Modulus of Deformability. The study verified that the Radius of Curvature values changed oscillating with its moisture content, although with no evidence of clear trend in function of this variable.

Table 2. Average values of Radius of Curvature of acerola seeds $\left(\times 10^{-3} \mathrm{~m}\right)$ in terms of each moisture contents (d.b.)

\begin{tabular}{lll}
\hline Moisture content (d.b.) & $\mathrm{r}$ & $\mathrm{R}$ \\
\hline 0.463 & 4.39 & 8.49 \\
0.370 & 4.50 & 8.64 \\
0.311 & 4.31 & 8.51 \\
0.258 & 4.43 & 9.28 \\
0.208 & 4.05 & 8.78 \\
0.166 & 4.07 & 9.05 \\
0.126 & 4.04 & 8.58 \\
\hline
\end{tabular}

Figure 2 shows the average values of the maximum compression force in function of its moisture content (d.b.) for different deformations. 


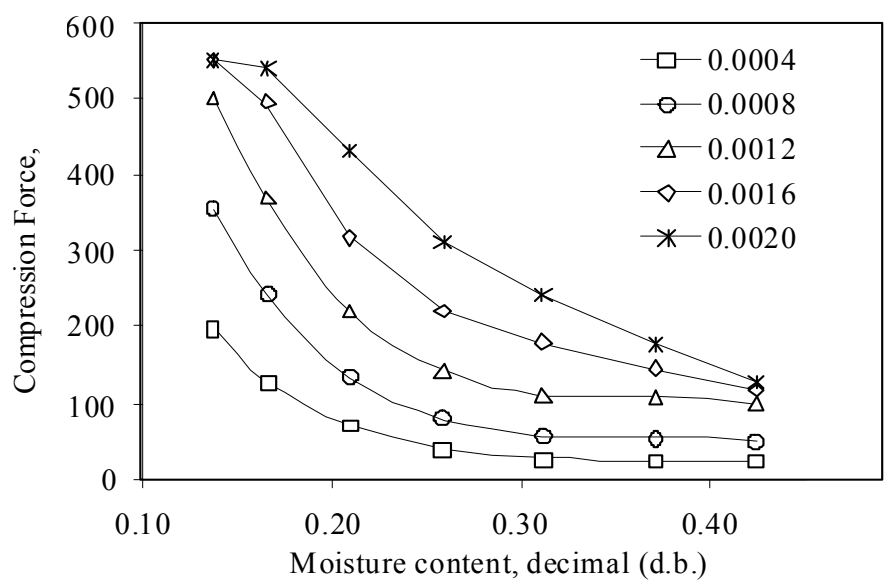

Figure 2. Average values of Maximum Compression Force $(\mathrm{N})$, in function of moisture content (d.b.) for the Deformations of $0.0004 ; 0.0008 ; 0.0012 ; 0.0016$ e $0.002 \mathrm{~m}$

Analyzing Figure 2, it can be verified that the Compression force needed for deforming the acerola seeds decreases with moisture content increase for the three compression positions. Similar results have been observed by Henry et al. (2000a) and by Ribeiro et al. (2005) for soybean in different moisture contents. The average force needed for different deformation of the product in function of its moisture content varied between 19.2 and 54.8 $\mathrm{N}$. The seeds with higher moisture content offered lower resistance to the compression increasing proportionally with moisture content reduction. This kind of tendency is due, probably to the gradual changes in the cellular matrix integrity occurring during moisture content reduction (Gupta \& Das, 2000).

As expected, increasing the deformation of the product, a very sensible increase was obtained on the seeds compression force.

From the compression force data, the Proportional Modulus of Deformability was obtained which presented the same behavior as the compression force in function of its moisture content.

Figure 3 presents the average values of the Proportional Modulus of Deformability in function of its moisture content (d.b.) for different acerola seeds deformation in its natural repose position.

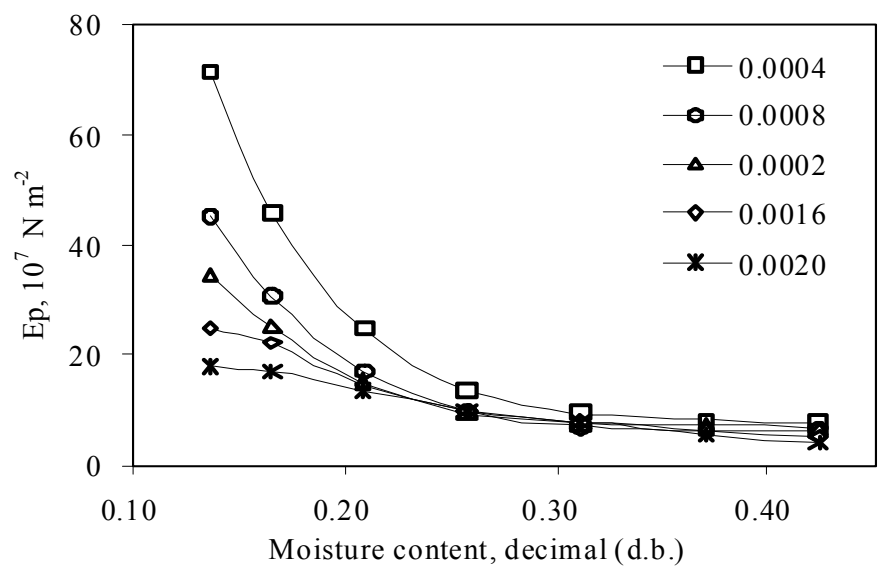

Figure 3. Average values of the Proportional Modulus of Deformability for acerola seeds $(\times 107 \mathrm{~Pa})$, for each deformation in function of its moisture content (d.b.)

Higher values of deformation mean that higher force should be applied on the product to obtain a certain deformation (Batista et al., 2003). It can be observed in Figure 3 that the values of the Proportional Modulus of Deformability increase with reduction of moisture content. These results confirm those observed by Ribeiro et al. (2005) for soybean and Batista et al. (2003) for coffee fruits. 
For the range of moisture content studied, the values of the Proportional Modulus of Deformability varied from $5.2 \times 10^{7}$ to $72.1 \times 10^{7} \mathrm{~Pa}$. These values are consistent to those observed by Ribeiro et al. (2005) for soybean who obtained the Proportional Modulus of Deformability of $2.31 \times 10^{7}$ to $10^{7} \mathrm{~Pa}$ for compression on its natural repose position in the moisture content range of 0.58 to 0.10 (d.b.) and the Deformation of the product of 0.002 $\mathrm{m}$. Couto et al. (2002) reported that the Proportional Modulus of Deformability of coffee, with moisture content of approximately 2.5 (d.b.), compression velocity of $1.7 \times 10^{-4} \mathrm{~m} \mathrm{~s}^{-1}$ and in the range of deformation of $1 \times 10^{-4}$ to $6 \times 10^{-4} \mathrm{~m}$, presented values within $1.0 \times 10^{7}$ to $3.0 \times 10^{7} \mathrm{~Pa}$ for green coffee fruits. Although Batista et al. (2003) found that the Proportional Modulus of Deformability of coffee fruits, for lower range of moisture content within 1.50 to 0.14 (d.b.), in all three coffee fruits ripeness stages, for moisture content from 1.50 to 0.14 (d.b.), in three ripeness stages, submitted to the drying temperature $\left(40,50\right.$ and $\left.60{ }^{\circ} \mathrm{C}\right)$, presented values within $2.0 \times 10^{7}$ to $18.0 \times 10^{7} \mathrm{~Pa}$ for coffee fruits in cherry stage of ripeness, $5.0 \times 10^{7}$ to $40.0 \times 10^{7} \mathrm{~Pa}$ for green stage and $1.0 \times 10^{7}$ to $50.0 \times 10^{7} \mathrm{~Pa}$ for greenish stage.

In the Figure 4 were presented the Elastic Coefficients values "a", "b" and "c" for natural repose position that were estimated through the Equation 2.
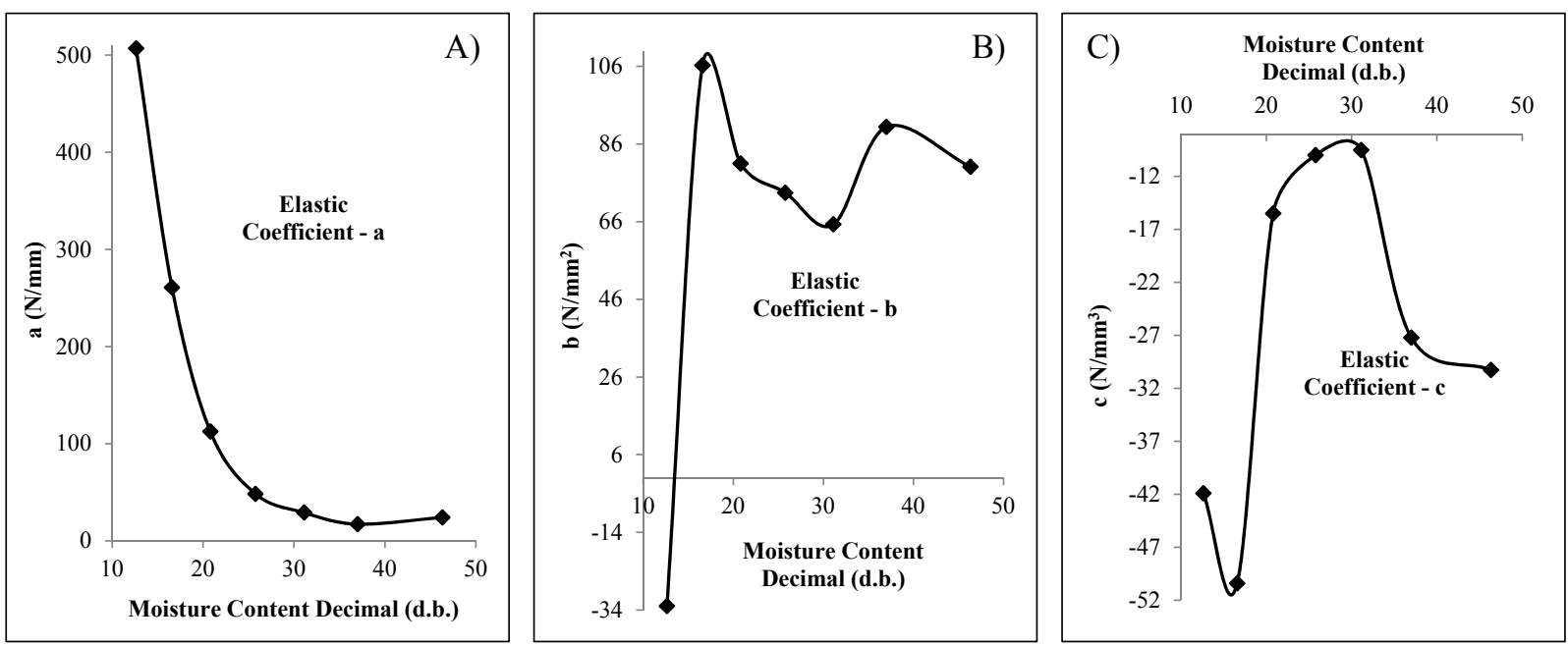

Figure 4. Elastic Coefficient values "a", "b" and "c", for each moisture contents of the acerola seeds compressed in its natural repose position

Describing the model indicated by Henry et al. (1996) infer that the signal of the coefficients "b" and "c" identifying the special conditions of the materials and of the test. For species non-damaged, however, the expected signal for the coefficients would be positive for " $b$ " and negative for "c". Besides, a positive value for "a" is always required for initial positive inclination of the curve.

According to Figure 4, it was observed that these characteristics were satisfied during the acerola seeds compression test, indicating that the experimental data follow the sigmoidal model, generally identified for biological materials (Henry et al., 1996). Compression under constant load affects the viscoelastic cell wall, causing cell to burst under high stress. This statement confirms the results found where fruits subjected to impact showed less bruise volume. Compression bruising occurs normally towards the direction of the force, commonly appearing as a line of cells whose walls have buckled and fractured which allows the cell contents to escape (Ferreira et al., 2008).

Figure 5 presents the Maximum Tangent and Secant values for compression test in the natural repose position for different moisture content. 

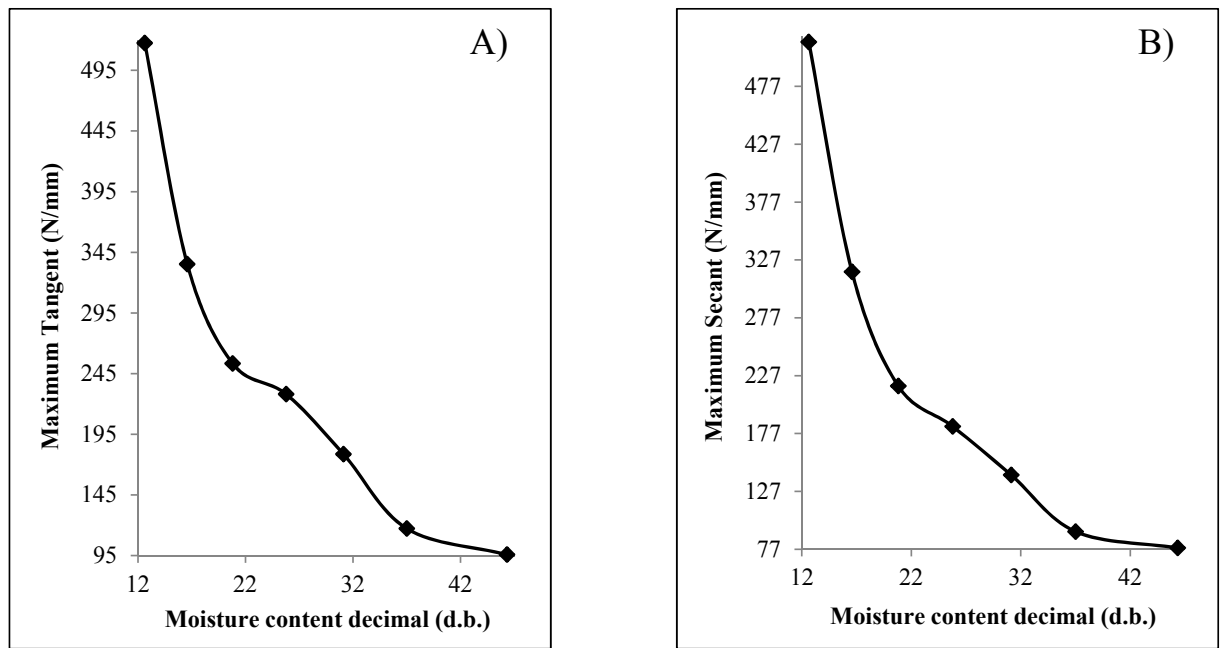

Figure 5. The values of the Maximum Tangent and Secant of the Force $x$ Deformation curve of the acerola seeds compressed in natural repose position for each moisture contents

The maximum Tangent and Secant were obtained for the deformations: $x=-2 b / 3 c$ and $x=-b / 6 c$, respectively. An increase on the Maximum Tangent and Secant values was verified when the moisture content diminishes, however the Maximum Tangent values presented higher magnitude in relation to the Maximum Secant, for the same moisture content, corroborating with the results obtained by Henry et al. (2000a), Pan and Tangratanavalee (2003), and Henry et al. (2000b).

\section{Conclusions}

The result of the test, which was force and deformation details obtained, and mechanical properties of calculated sample. The compression force necessary to deform the acerola seeds decreases as the moisture content increases presenting different deformations, with values within 19.2 and $548.8 \mathrm{~N}$. The Proportional Modulus of Deformability increases with moisture content reduction, with values in the range of moisture content of this work between 5.2 to $72.1 \times 10^{7} \mathrm{~Pa}$. The sigmoidal model represents adequately the resistance of acerola seeds compression for different moisture content analyzed.

\section{References}

ASAE (American Society of Agricultural Engineers). (2003). Agricultural Engineers Yearbook of Standards. St. Joseph, MI.

Bargale-Praveen, C., Irudayaraj, J., \& Marquist, B. (1995). Studies on rheological behaviour of canola and wheat. J. Agric. Engineering Research, 61, 267-274. https://doi.org/10.1006/jaer.1995.1054

Batista, C. S., Couto, S. M., Cecon, P. R., \& Peixoto, A. B. (2003). The effect of the drying air temperature, moisture content and ripeness stage of the coffee fruits (Coffea arabica L.) on the modulus of deformability. Brazilian J. Storage, 6, 42-53.

Correa, P. C., Resende, O., Ribeiro, D. M., Jarén, C., \& Arazuri, S. (2008). Resistence of edible beans to compression. J. Food Engineering, 86(1), 172-177. https://doi.org/10.1016/j.jfoodeng.2007.09.021

Costa, L. C., Pavani, M. C. M. D., Moro, F. V., \& Perecin, D. (2003). Viabilidade de sementes de acerola (Malpighia emarginata D.C.): Avaliação da vitalidade dos tecidos. J. Fruit Brazilian, 25(3), 532-534.

Couto, S. A., Batista, C. S., Peixoto, A. B., \& Devilla, I. A. (2002). Mechanical behavior of the coffee fruits: modulus of deformability. Brazilian Agric. Engineering and Environmental J., 6(2), 285-294.

Ferreira, M. D., Sargent, S. A., Brecht, J. K., \& Chandler, C. K. (2008). Strawberry fruit resistance to simulated handling. Scientia Agricola, 65(5), 490-495. https://doi.org/10.1590/S0103-90162008000500007

Figueiredo Neto, A., Almeida, F. A. C., Olivier, N. C., \& Irmão, M. A. S. (2013). Mechanical behavior of pumpkin fruits subjected to compression during maturation. Pesq. Agropec. Trop., 43(3), 223-231. https://doi.org/10.1590/S1983-40632013000300003

Gupta, R. K., \& Das, S. K. (2000). Fracture resistance of sunflower seed and kernel to compressive loading. $J$. Food Engineering, 46, 1-8. https://doi.org/10.1016/S0260-8774(00)00061-3 
Gustafson, R. J., \& Hall, G. E. (1972). Density and porosity changes of shelled corn during drying. Transaction of the ASAE, 15(1), 523-525.

Henry, Z. A., Su, B., \& Zhang, H. (2000a). Resistance of soya beans to compression. J. Agric. Engineering Research, 76, 175-181. https://doi.org/10.1006/jaer.2000.0546

Henry, Z. A., Zhang, H., \& Onks, D. (1996). Generalized model of resistance to strain of cellular material. American Society of Agricultural Engineers, 96, 1-26.

Henry, Z. A., Zhang, H., Su, B., \& Onks, D. (2000b). Elastic properties of the tobacco leaf. J. Agric. Engineering Research, 76, 101-110. https://doi.org/10.1006/jaer.2000.0536

Jamieson, A. R., Forney, C. F., Richards, K. U. K. G., Linna, M. M., \& Parikka, P. (2002). Strawberry fruit characteristics that contribute to postharvest quality. Acta Horticulturae, 567, 723-726. https://doi.org/ 10.17660/ActaHortic.2002.567.158

Li, Y., Zhang, Q., Puri, V. M., \& Mambeck, H. B. (1989). Physical properties effect on stress-strain behavior of wheat en masse - Part I. Load response dependence on initial bulk density in moisture content. Transactions of the ASAE, 32(1), 194-202. https://doi.org/10.13031/2013.30982

Liu, M., Haghighi, K., Stroshine, R. L., \& Ting, E. C. (1990). Mechanical properties of soybean cotyledon and failure strength of soybean kernel. Transactions of the American Society of Agricultural Engineers, 33, 559-565. https://doi.org/10.13031/2013.31366

Mohsenin, N. N. (1986). Physical properties of plant and animal materials (p. 841). New York: Gordon and Breach Publishers.

Oliveros-Tascon, C. E., Montoya-Restrepo, E. C., \& Ayala, A. A. (2002). The effect of the coffee grain worm on the grain firmness in cherry ripeness stages and for moist and dry parchment coffee. Cenicafe, 53, 25-33.

Pan, Z., \& Tangratanavalee, W. (2003). Characteristics of soybeans as affected by soaking conditions. Food Sci. Technology, 36, 143-151. https://doi.org/10.1016/S0023-6438(02)00202-5

Reis, D. S., Figueiredo Neto, A, Ferraz, A. V., \& Freitas, S. T. (2017). Production and storage stability of acerola flour dehydrated at different temperatures. Braz. J. Food Technol., 20, e2015083, https://doi.org/10.1590/ $1981-6723.8315$

Shirmohammadi, M., \& Yarlagadda, P. (2012). Experimental study on mechanical properties of pumpkin tissue. $J$. Achievements in Materials and Manufacturing Engineering, 54(1), 16-24.

White, G. M., Ross, I. J., \& Poneleit, C. G. (1982). Stress crack development in popcorn as influenced by drying and rehydration processes. Transactions of the ASAE, 25(3), 768-772. https://doi.org/10.13031/2013.33610

Zhang, Q., Li, Y., Puri, V. M., \& Manbeck, H. B. (1989). Physical properties effect on stress-strain behavior of wheat en masse - Part II. Constitutive elastoplastic parameter dependence on initial bulk density and moisture content. Transactions of the ASAE, 32(1), 203-209. https://doi.org/10.13031/2013.30983

\section{Copyrights}

Copyright for this article is retained by the author(s), with first publication rights granted to the journal.

This is an open-access article distributed under the terms and conditions of the Creative Commons Attribution license (http://creativecommons.org/licenses/by/4.0/). 